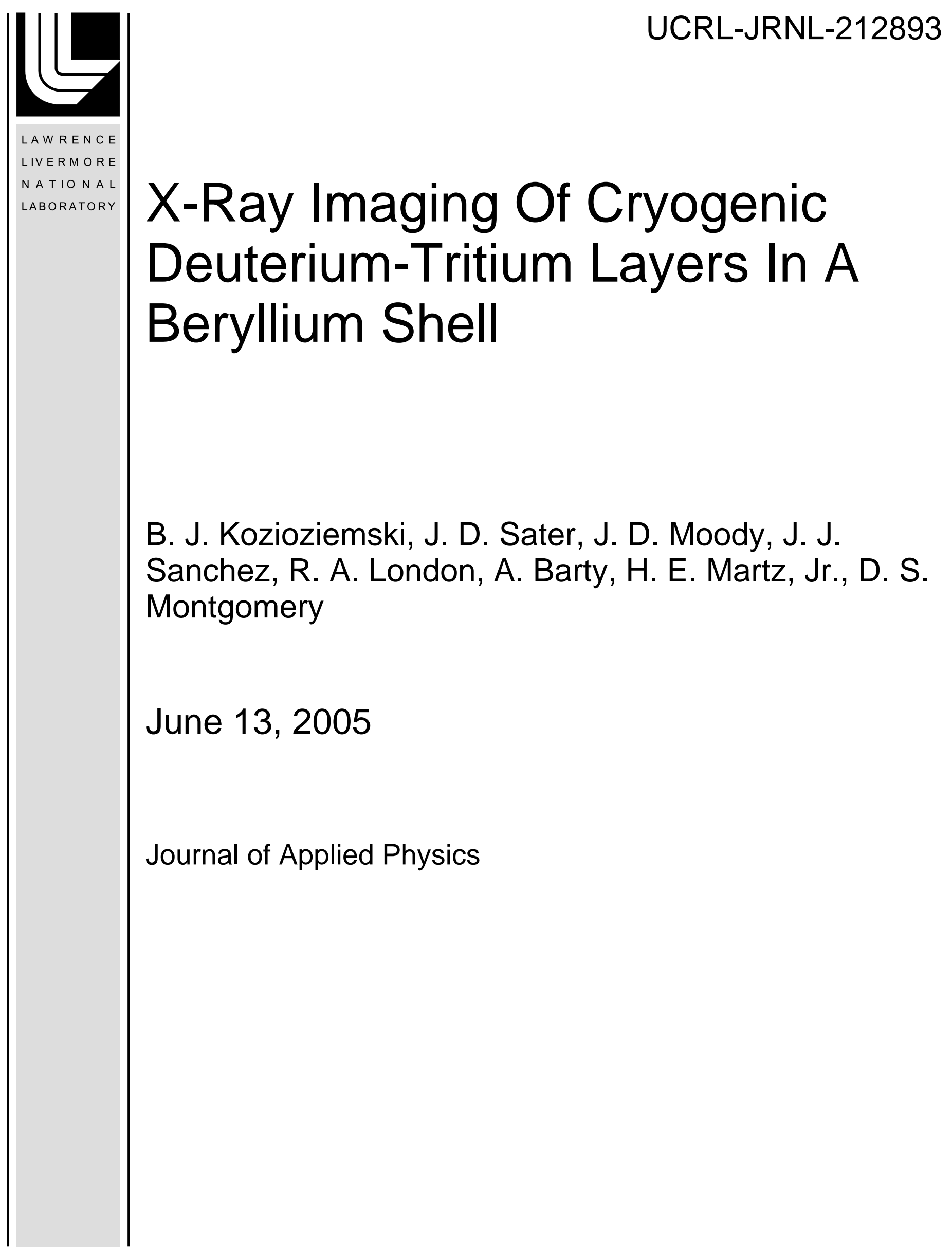


This document was prepared as an account of work sponsored by an agency of the United States Government. Neither the United States Government nor the University of California nor any of their employees, makes any warranty, express or implied, or assumes any legal liability or responsibility for the accuracy, completeness, or usefulness of any information, apparatus, product, or process disclosed, or represents that its use would not infringe privately owned rights. Reference herein to any specific commercial product, process, or service by trade name, trademark, manufacturer, or otherwise, does not necessarily constitute or imply its endorsement, recommendation, or favoring by the United States Government or the University of California. The views and opinions of authors expressed herein do not necessarily state or reflect those of the United States Government or the University of California, and shall not be used for advertising or product endorsement purposes. 


\title{
X-ray imaging of cryogenic deuterium-tritium layers in a beryllium shell
}

\author{
B. J. Kozioziemski, J. D. Sater, J. D. Moody, J. J. Sanchez, R. A. London, A. Barty, and H. E. Martz Jr \\ Lawrence Livermore National Laboratory, Livermore CA 94551 \\ D. S. Montgomery \\ Physics Division, Los Alamos National Laboratory, Los Alamos, NM 87545
}

(Dated: June 1, 2005)

\begin{abstract}
Solid deuterium-tritium (D-T) fuel layers inside copper doped beryllium shells are robust inertial confinement fusion fuel pellets. This paper describes the first characterization of such layers using phase-contrast x-ray imaging. Good agreement is found between calculation and experimental contrast at the layer interfaces. Uniform solid D-T layers and their response to thermal asymmetries were measured in the $\mathrm{Be}(\mathrm{Cu})$ shell. The solid $\mathrm{D}-\mathrm{T}$ redistribution time contrast was measured to be 28 minutes in the $\mathrm{Be}(\mathrm{Cu})$ shell.
\end{abstract}

PACS numbers:

\section{INTRODUCTION}

The current design for the National Ignition Facility (NIF) inertial confinement fusion fuel pellet is a spherical, solid deuterium-tritium (D-T) fuel layer inside of a copper doped beryllium, $\mathrm{Be}(\mathrm{Cu})$, shell. This design can tolerate roughner D-T surfaces, compared to plastic ablators which require less than $1 \mu \mathrm{m}$ RMS D-T surfaces to ignite. [1, 2] Characterization of the solid D-T surface roughness is requried to compare ignition experiments with simulations. However, only limited characterization of the solid D-T fuel layer inside of the $\mathrm{Be}(\mathrm{Cu})$ shell has been possible. [3-5] Absorption x-ray imaging cannot be used to characterize the $\mathrm{D}$ - $\mathrm{T}$ surface inside of $\mathrm{Be}(\mathrm{Cu})$ shells because the opacity of the $\mathrm{D}-\mathrm{T}$ is 4 orders of magnitude lower than that of the $\mathrm{Be}(\mathrm{Cu})$. However, the difference from vacuum in the real part of the refractive index for solid D-T at x-ray wavelengths is within a factor of 10 of that of $\mathrm{Be}(\mathrm{Cu}) .[6,7]$ Phase-contrast enhanced imaging methods have been demonstrated for other materials with similar characteristics. [8-15] Recent advances in phase-contrast enhanced x-ray imaging using laboratory $\mathrm{x}$-ray sources makes $\mathrm{x}$-ray imaging of the solid $\mathrm{D}-\mathrm{T}$ layer possible.[16-18]

Calculations for phase-contrast x-ray imaging showed that the D-T surface should be rendered visible in the $\mathrm{Be}(\mathrm{Cu})$ shell using a micro-focus source.[7] Models also demonstrate that the surface roughness can be accurately characterized. $[7,10]$ Experiments at the Advanced Photon Source using surrogate plastic and foam shells verified that a rough surface could be imaged.[10] This paper describes characterization of actual solid D-T layers inside a $\mathrm{Be}(\mathrm{Cu})$ shell using a commercial micro-focus x-ray source.

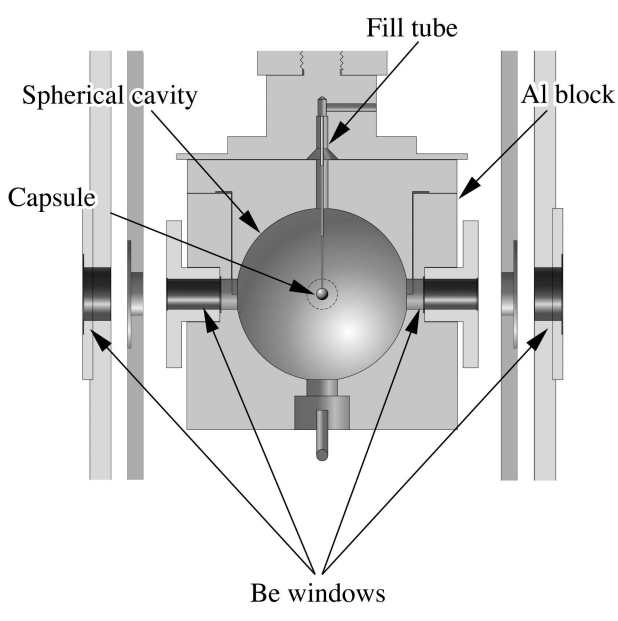

FIG. 1: The $\mathrm{Be}(\mathrm{Cu})$ shell is centered in a $25.4 \mathrm{~mm}$ diameter spherical cavity inside of an Al block. Be windows $200 \mu \mathrm{m}$ thick allow transmission of x-rays for imaging. The shell is suspended from a fill tube and the Al block is attached to the cold-tip of a flow cryostat.

\section{EXPERIMENT}

A mixture of $25 \%$ deuterium, $25 \%$ tritium and $50 \%$ deuterium-tritium molecules is defined as D-T. Solid D$\mathrm{T}$, by virtue of its relatively high vapor pressure and radioactive self-heating, forms an equilibrium surface that conforms to an isotherm.[19-22] Solid D-T layers grown in an environment with spherical isotherms will thus be spherical as well. Uniformly thick spherical D-T layers have been characterized inside of transparent plastic shells using visible light imaging.[22-25] In those experiments, the shell was placed inside of a spherical copper or aluminum cavity with a helium $\left({ }^{4} \mathrm{He}\right)$ atmosphere to ensure a spherical isothermal surface at the shell. The same approach is employed in this experiment.

A $2.154 \mathrm{~mm}$ diameter, $105 \mu \mathrm{m}$ wall Be shell doped with 0.9 atomic percent $\mathrm{Cu}$ was made by sputter deposi- 
tion of $\mathrm{Be}$ and $\mathrm{Cu}$ on a plastic mandrel.[26, 27] A $50 \mu \mathrm{m}$ hole, with a $70 \mu \mathrm{m}$ counter-bore was mechanically drilled through the shell. The $12 \mu \mathrm{m}$ thick plastic mandrel was removed from the shell by pyrolysis in an oxygen atmosphere. A glass tube was glued into the hole and used to fill the $\mathrm{Be}(\mathrm{Cu})$ shell with $\mathrm{D}-\mathrm{T}$. The shell was placed at the center of a $25.4 \mathrm{~mm}$ diameter spherical cavity machined into an aluminum block. Aluminum's high thermal conductivity minimizes temperature variations at the cavity surface and ensures that the shell is in a spherically symmetric temperature field. Figure 1 shows the shell inside of the cavity which was placed on the cold-tip of a flow cryostat. Four equally spaced holes on the midplane were drilled through the aluminum to provide viewing access to the shell. $200 \mu \mathrm{m}$ thick beryllium windows covered the holes along one axis and optical windows were used along the perpendicular axis.

All of the data reported in this article was collected with the Lawrence Livermore National Laboratory's KCAT system. This is a modular x-ray microscope that can acquire both digital radiography and tomography data.[28] KCAT employs a $150 \mathrm{kV}$ polychromatic Kevex sealed-tube $\mathrm{x}$-ray source. The $\mathrm{x}$-ray tube was operated at $60 \mathrm{kV}$ and $0.082 \mathrm{~mA}$ current with a tungsten anode. The x-ray spot size is between $10-20 \mu \mathrm{m}$ fullwidth at half maximum (FWHM) with these parameters

An Industrial Quality, Inc. terbium oxide doped scintillating glass plate converts $\mathrm{x}$-rays to visible light. The scintillator is optically coupled by a Nikon $60 \mathrm{~mm}$ MicroNikkor lens to a cooled 3072x2048 Quantix CCD camera. The camera has 14-bit digital resolution and a detector pitch of $9 \mu \mathrm{m}$. The low dark current of the cooled camera enabled long integration times necessary for obtaining high signal-to-noise radiographs.

The source to shell distance was $70 \pm 5 \mathrm{~mm}$. The shell to scintillator distance was $205 \pm 5 \mathrm{~mm}$, giving a geometric magnification of 3.9x. The pixel size at the shell is $2.3 \mu \mathrm{m}$. The penumbral blurring due to the finite spot size and geometric magnification is given by

$$
\sigma=a \frac{(M-1)}{M}
$$

where $a$ is the spot size and $M$ is the geometric magnification. The expected blurring is 8-16 $\mu \mathrm{m}$ FWHM.

\section{$\mathrm{D}_{2}$ and D-T fills}

Figure 2 shows an x-ray image of $\mathrm{D}$ - $\mathrm{T}$ in a $\mathrm{Be}(\mathrm{Cu})$ shell which has been processed with a band-pass filter. The left image shows the $\mathrm{Be}(\mathrm{Cu})$ shell partially filled with liquid D-T. The right image shows solid D-T after the $\mathrm{Be}(\mathrm{Cu})$ shell was cooled to $19.3 \mathrm{~K}(0.4 \mathrm{~K}$ below the triple-point temperature of D-T) and held at a constant temperature for 4 hours. In both cases, a dark band indicates the inner D-T surface. The solid is in a circular

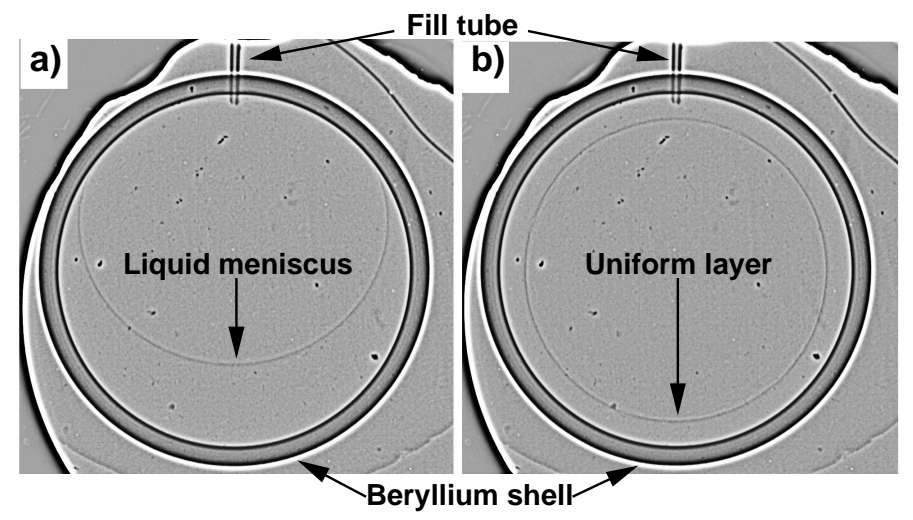

FIG. 2: X-ray image with (a) liquid D-T and (b) solid D-T in the $\mathrm{Be}(\mathrm{Cu})$ shell. The image was processed with a band-pass filter to enhance the contrast of the D-T surfaces. In both cases gravity is down. The liquid is slowly cooled to solid, which beta-layers to a uniformly thick spherical shape.

shape, as expected based on previous experiments with optically transparent shells. The exposure time for these images was 30 minutes.

\section{IMAGE ANALYSIS}

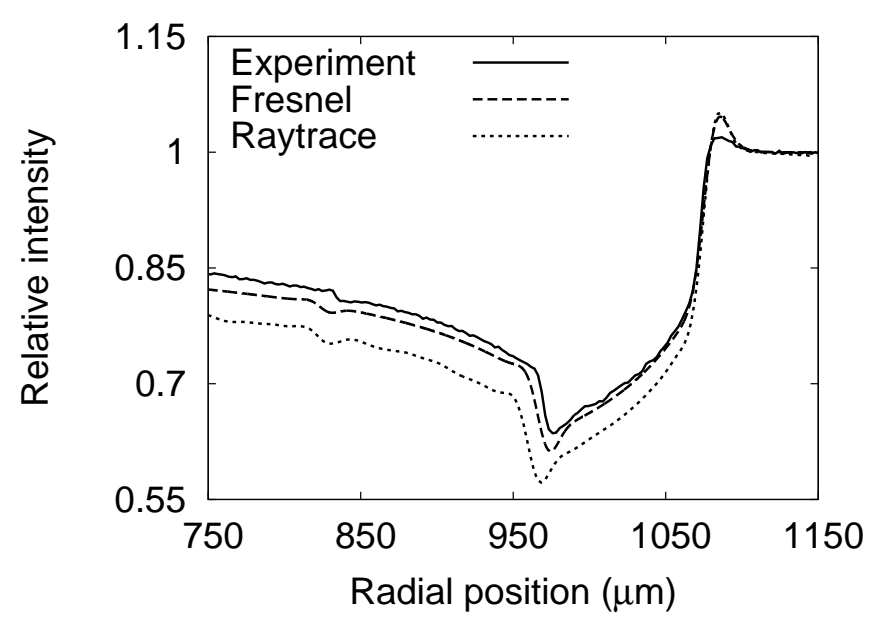

FIG. 3: Comparison of experimental and model results for the $\mathrm{Be}(\mathrm{Cu})$ shell with solid D-T layer. The Fresnel propagation model uses the experimental geometry with the calculated $\mathrm{x}-$ ray spectrum in Fig. 6 and scintillator response. A raytrace calculation is also shown, where the x-ray spectrum is approximated by discrete wavelenths. Both model calculations used a $16 \mu \mathrm{m}$ FWHM Gaussian blur.

Phase-contrast enhanced x-ray imaging of the solid D-T surface was predicted using computational modeling. Comparison of the experimental data with the calculation aids future improvements in the experimental data and validates the models. Two different modeling methods are tested here. The first modeling tech- 
nique solves the Fresnel diffraction integral using Fourier methods.[7, 29] The complex electric field is computed for a plane wave of x-rays transmitted through a synthesized object, and the exit wave is propagated to the detector plane by solving the Fresnel integral. This method is accurate for both refractive and diffractive effects. The second model is a Monte Carlo raytrace which accounts only for refraction. [30]

The Fresnel propagation model starts with an incident plane-wave of constant amplitude. The wave phase and amplitude is altered by the object, calculated using a thin-object approximation, where the phase delay and attenuation are obtained by integrating through the object. The wave-front is then propagated to the detector plane where the image is formed. The plane-wave calculation can be transformed to a spherical wave-calculation by accounting for geometric magnification which emulates a point-source of x-rays rays at a finite distance from the object.[18, 31] This calculation is repeated for 250 discrete wavelengths from $1 \mathrm{keV}$ to $30 \mathrm{keV}$ in the $\mathrm{x}$-ray emission spectrum and summed with weights proportional to the source spectrum. The weighting also incorporates the scintillator absorption as well as transmission through the beryllium cryostat windows. The resulting intensity distribution is rebinned consistent with the physical pixel size of the detector and convolved with a Gaussian point-spread-function to approximate both the finite source size and any blur by the detector.

Monte Carlo raytracing used the TracePro[30] commercial package. The object model is three-dimensional, however, it does not include diffraction effects. The model used the point-projection geometry and detector pixel size consistent with the experiment. However, the $\mathrm{x}$-ray spectrum was approximated with only eight distinct x-ray energies to limit computational time. The eight energies were chosen to span the total $\mathrm{x}$-ray spectrum with a relative intensity weighting consistent with the x-ray spectrum, scintillator response, and transmission through the beryllium windows.

Figure 3 compares line-outs of the experimental image of solid $\mathrm{D}-\mathrm{T}$ in the $\mathrm{Be}(\mathrm{Cu})$ shell with the Fresnel and raytrace model calculations. Both models used a 16 $\mu \mathrm{m}$ FWHM Gaussian point-spread-function at the object plane, consistent with the expected experimental value, and a uniform doping of 0.9 atomic percent of copper in the beryllium shell. Both models demonstrate good agreement with the general shape of the experimental data. They also show similar contrast at the outer edge of the $\mathrm{Be}(\mathrm{Cu})$ shell, which is higher than the experimental value. The Fresnel propagation calculation has better agreement with the overall intensity because the full spectrum is included. The raytrace shows good agreement with the Fresnel calculation because the system resolution is not sufficient to resolve diffraction.

\section{Layering time constant}

Tritium beta-decay is a source of heat in the D-T solid. Therefore, the temperature of the D-T surface where the solid is thick is higher than the region where the solid is thin. The differential vapor pressure due to the temperature difference results in sublimation from the thick region and recondensation at the thin region. This process, known as beta-layering, has been observed in numerous geometries and materials.[19-22, 32] These observations determined that the redistribution rate is an exponential function of time and depends on the amount of ${ }^{3} \mathrm{He}$ in the sample. As ${ }^{3} \mathrm{He}$ accumulates from the beta-decay, the redistribution time constant increases. A shell with a high thermal conductivity has a redistribution time constant that increases more rapidly with ${ }^{3} \mathrm{He}$ than a low thermal conductivity material.

The purpose of measuring the layering time constant in beryllium is to verify that the layering time constant is the same for $\mathrm{D}-\mathrm{T}$ in $\mathrm{Be}(\mathrm{Cu})$ shells as in other materials, provided the ${ }^{3} \mathrm{He}$ concentration is low. This particular measurement was done immediately after filling the shell so that there is very little ${ }^{3} \mathrm{He}$ in the shell.

The layering time constant was determined by measuring the thickness of the D-T solid as a function of time. The D-T was quickly frozen so that the majority of the mass started at the bottom of the shell, where the liquid was located. The D-T layer near the top of the shell then grew with time as the D-T re-distributed itself. Thirty second exposures were taken every 2-3 minutes over a period of 2 hours. The image quality for these short exposure images was sufficient to locate the ice surface, but the signal-to-noise was too low to make a detailed analysis of the ice layer. A final image was taken 4.5 hours after the initial freeze.

The D-T layer thickness is determined from a single radiographic image by measuring from the shell-ice interface to the ice-vapor edge. The thickness was measured at the angular positions, 30 and -23 degrees from the fill tube. The results, shown in Fig. 4, give time constants of 27.0 and 29.7 minutes, in good agreement with previous measurements for D-T of 30 minutes.[19, 20, 32] The time constant is expected to change with the sample age, due to buildup of ${ }^{3} \mathrm{He}$, and will be measured in the future.

\section{Layer roughness vs Temperature}

The low image signal to noise ratio prevented an accurate spectral characterization of the layer roughness. However, the data showed distinct changes in low Fourier mode amplitudes with temperature. The measured RMS roughness for modes 1 to 5 is about $2 \mu \mathrm{m}$ for the first layers grown in the $\mathrm{Be}(\mathrm{Cu})$ shell within $1 \mathrm{~K}$ of the triple point temperature. The RMS increased to over $3 \mu \mathrm{m}$ 


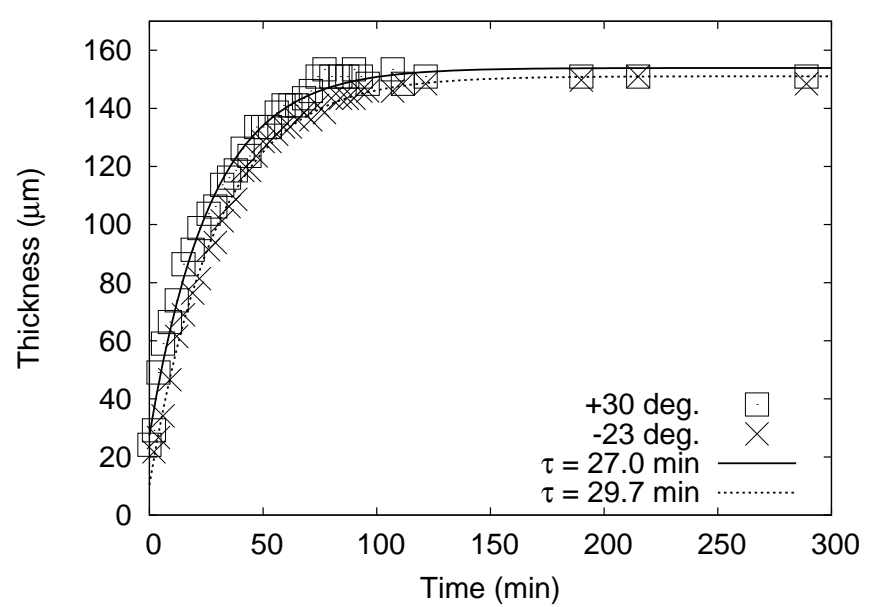

FIG. 4: Layer thickness as a function of time (points) at +30 and -23 degrees relative to the fill tube and the resulting fit to an exponential (lines). The time constants are 27.0 minutes and 29.7 minutes.

when the layer was cooled for 3 hours to reach $5 \mathrm{~K}$. The radiographic projections show features which may be cracks in the ice layer, however the present signal-tonoise ratio was not sufficient to quantify their effect on the surface roughness.

\section{Layer movement due to convection}

The solid D-T layer will move in the presence of temperature inhomogeneities in the shell. Convection of the ${ }^{4} \mathrm{He}$ gas in the spherical cavity perturbs the temperature profile of the ideally isothermal shell.[33]. Convection of the ${ }^{4} \mathrm{He}$ gas by the $\mathrm{D}$ - $\mathrm{T}$ self-heating distorts the temperature field at the D-T surface and increases with increasing ${ }^{4} \mathrm{He}$ gas pressure. Convective cooling makes the top of the shell warmer, with the ice becoming thinner there.

Increasing the ${ }^{4} \mathrm{He}$ gas pressure caused a distortion of the layer shape as shown in figure 5 . When the ${ }^{4} \mathrm{He}$ gas pressure was reduced, the layer returned to its original shape. The shape is expected to be symmetric about the vertical axis, so the radial position of the surface may be described by Legendre polynomials, $\mathrm{P}_{l}$. The lowest mode is the most strongly influenced by convection. A $17 \mu \mathrm{m} \mathrm{P}_{1}$ amplitude was observed with 300 torr of ${ }^{4} \mathrm{He}$ gas. The $\mathrm{P}_{1}$ amplitude was $-1 \mu \mathrm{m}$ when the ${ }^{4} \mathrm{He}$ pressure was 10 torr.

The above results were compared to a computational model of the effect of convection on a D-T layer. The COSMOS[34] code was used to model convection and has been described previously for a similar application. [33] The sputtered $\mathrm{Be}(\mathrm{Cu})$ thermal conductivity has not been measured so its value was set as a free parameter in the model. The layer shape was input based on the experimental measurements, as was the ${ }^{4} \mathrm{He}$ gas

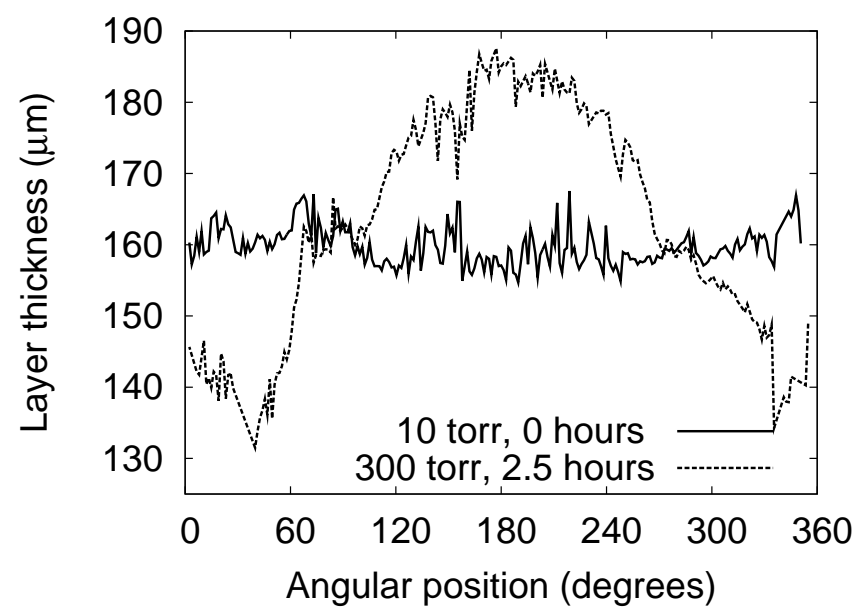

FIG. 5: D-T layer thickness as a function of angle as the ${ }^{4} \mathrm{He}$ exchange gas is increased in the layering sphere. Convection increases with increasing ${ }^{4} \mathrm{He}$ pressure, leading to layer deformations. Zero degrees is in the direction of the fill-tube, opposite gravity.

pressure. The $\mathrm{Be}(\mathrm{Cu})$ conductivity, $k_{s}$ was varied until the ice surface was isothermal. The best agreement between the model and experiment was occured when $k_{s}=$ $12.6 \mathrm{~W} /(\mathrm{m} \cdot \mathrm{K})$. For comparison, Be thermal conductivity at $20 \mathrm{~K}$ is between 50 and $80 \mathrm{~W} /(\mathrm{m} \cdot \mathrm{K})$ for pressed samples, and $15 \mathrm{~W} /(\mathrm{m} \cdot \mathrm{K})$ for an annealed powder.[35] It has been observed that sputtered $\mathrm{Be}(\mathrm{Cu})$ tends to have columnar growth in the radial direction and a significant density of voids.[26] This will lead to a reduced thermal conductivity in the angular direction. Because it is the angular temperature variation along the shell surface that causes the D-T layer to move, the $\mathrm{D}$ - $\mathrm{T}$ layer shape is more sensitive to the angular thermal conductivity than the radial. Thus, the thermal conductivity value derived from the experiment and model is closer to the angular.

\section{Heating due to absorbed x-rays}

The $\mathrm{Be}(\mathrm{Cu})$ shell can absorb a significant fraction of the x-rays impinging upon it, depending upon the x-ray energy. This leads to an overall increase and an asymmetry in the shell temperature. As seen previously, thermal asymmetry will cause the solid D-T layer to depart from an ideal spherical shell. Since the x-ray absorption in the solid D-T is very weak compared to the $\mathrm{Be}(\mathrm{Cu})$, this effect is estimated by calculating only the heating of the $\mathrm{Be}(\mathrm{Cu})$ shell. The volumetric heating rate is given by

$$
Q_{x}(r, \theta)=\int \alpha(\lambda) F_{0}(\lambda) \exp [-\alpha(\lambda) \Delta z(r, \theta)] d \lambda,
$$

here $r$ and $\theta$ are polar coordinates describing the position in the shell, $\alpha(\lambda)$ is the wavelength dependent x-ray ab- 
sorption coefficient, $F_{0}(\lambda)$ is the wavelength dependent incident flux, and $\Delta z$ is the x-ray path length through the shell to the position $r, \theta$. The center of the shell is at $r=0$, and the x-ray source is from the $\theta=0$ direction. Straight, parallel rays are assumed, justified by the small refractive bending and the large distance from the source to the shell.

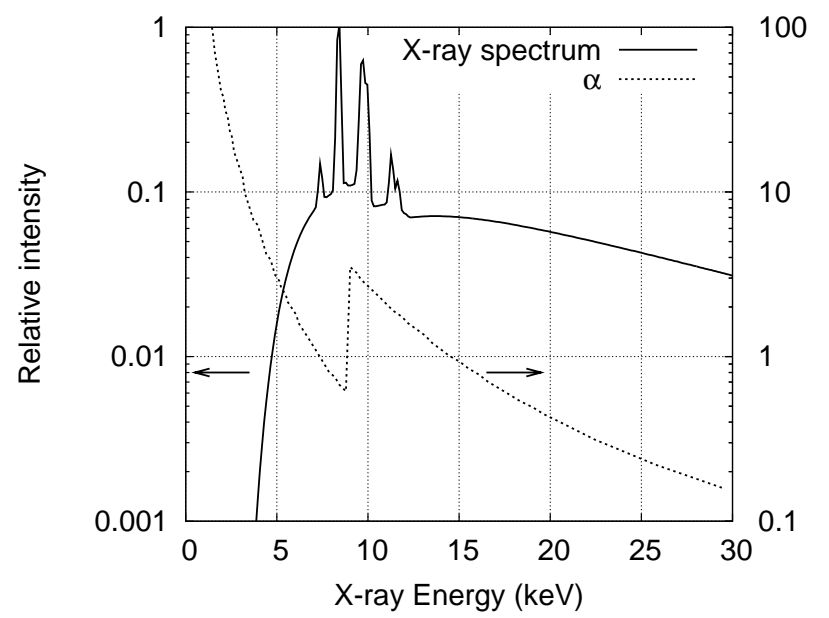

FIG. 6: Calculated x-ray spectrum from tungsten anode driven at $60 \mathrm{kV}$ (solid) and $\mathrm{Be}(\mathrm{Cu})$ absorption coefficient (dashed) as a function of energy. $\mathrm{A} \mathrm{Be}(\mathrm{Cu})$ shell has significant absorption at the tungsten characteristic lines.

The x-ray intensity and absorption coefficient are shown in figure 6 . The $\mathrm{x}$-ray spectrum is calculated with the code TUBEDET[36] for the Thermo-Kevex tube operating parameters of $60 \mathrm{kV}$ and $0.082 \mathrm{~mA}$. The absorption spectrum is obtained from the Lawrence Berkeley Laboratory Center for X-ray Optics website[6]. Evaluating Eqn. 2 for the shell dimensions specified above gives the heating rate shown in figure 7 . The calculated peak heating using the Kevex spectrum and the $\mathrm{Be}(\mathrm{Cu})$ absorption is $270 \mathrm{~W} / \mathrm{m}^{3}$ or about $1 / 200 \mathrm{Q}_{\mathrm{DT}}$, where $\mathrm{Q}_{\mathrm{DT}}$ $=5 \times 10^{4} \mathrm{~W} / \mathrm{m}^{3}$ is the native beta-decay heating rate in the $\mathrm{D}-\mathrm{T}$. The $\mathrm{x}$-ray flux is reduced as the $\mathrm{x}$-rays propagate through the shell. Thus the heating is strongest on the side of the shell nearest the $\mathrm{x}$-ray source and weakest just beyond the midplane $(\theta=90)$ where the $\mathrm{x}$-ray pathlength through the shell is longest.

The heating rate is then used as input to a heat conduction calculation to determine the expected equilibrium D-T ice distribution.[34] In accordance with the beta-layering process, the equilibrium configuration is expected to occur when the inner ice surface is isothermal. The calculations are done with an iterative procedure, varying the ice distribution to minimize the temperature variation on the inner surface.

Using the value of $12.6 \mathrm{~W} /(\mathrm{m} \cdot \mathrm{K})$ for the sputtered $\mathrm{Be}(\mathrm{Cu})$ thermal conductivity, the ice layer is offset by $0.05 \mu \mathrm{m}$ away from the x-ray source. Increasing the flux

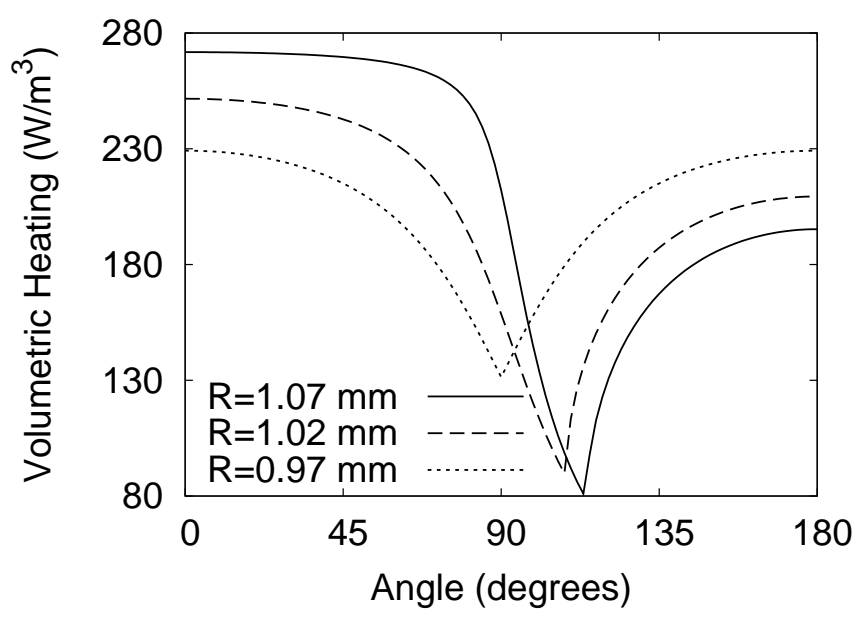

FIG. 7: Spatial dependence of the x-ray heating profile in a $\mathrm{Be}(\mathrm{Cu})$ shell for several radial positions $\mathrm{R}$. The heating is strongest at the outer surface and has a large variation with angle closer to the center. The $\mathrm{W}$ source spectrum shown in Fig. 6 was used to produce the heating.

by a factor of 10-20 would make the temperature perturbation and resulting D-T layer thickness perturbation of $0.5-1 \mu \mathrm{m}$ enough to impact ignition experiments. A maximum incident power of $10 \mu \mathrm{W}$ on the shell is tolerable from a tungsten source. The maximum power is increased to $20 \mu \mathrm{W}$ when only $8 \mathrm{keV}$ x-rays, such as those from a $\mathrm{Cu} \mathrm{K}-\alpha$ x-ray emission line, are used.

\section{CONCLUSIONS}

Phase-contrast x-ray imaging of a solid D-T layer inside a copper doped beryllium shell was demonstrated. The relatively large x-ray source size and low flux required long exposure times. Comparison between the calculated and experimental images show good agreement. This imaging method is an important enabling technology for the National Ignition Facility.

Using the phase-contrast $\mathrm{x}$-ray images, measurement of the solid D-T layering time-constant was 28 minutes. Future experiments will measure the layering time constant as the ${ }^{3} \mathrm{He}$ builds up. The effect of convection in the ${ }^{4} \mathrm{He}$ gas on the solid D-T layer was used to estimate the $\mathrm{Be}(\mathrm{Cu})$ thermal conductivity to be $12.6 \mathrm{~W} /(\mathrm{m} \cdot \mathrm{K})$. This thermal conductivity value made it possible to set limits to the x-ray flux necessary to limit thermal asymmetries in the $\mathrm{Be}(\mathrm{Cu})$ shell and the resulting D-T thickness variation.

While the overall layer shape could be observed, the limited resolution and signal-to-noise prevented accurate characterization of high frequency roughness on the D-T surface. Future experiments and modeling will explore imaging with finer resolution.

This work was performed under the auspices of the 
U.S. Department of Energy by the University of California, Lawrence Livermore National Laboratory under contract No. W-7405-Eng-48 and by the Los Alamos National Laboratory under contract No. W-7405-Eng-36.

[1] D. C. Wilson, P. A. Bradley, N. M. Hoffman, F. J. Swenson, D. P. Smitherman, R. E. Chrien, R. W. Margevicius, D. J. Thoma, L. R. Foreman, J. K. Hoffer, et al., Physics of Plasmas 5, 1953 (1998).

[2] S. W. Haan, T. Dittrich, G. Strobel, S. Hatchett, D. Hinkel, M. Marinak, D. Munro, O. Jones, S. Pollaine, and L. Suter, Fusion Technology 41, 164 (2002).

[3] T. J. Asaki, J. K. Hoffer, and J. D. Sheliak, Fusion Technology 33, 171 (1998).

[4] T. Hale, T. Asaki, K. Telschow, and J. Hoffer, in SPIEInt. Soc. Opt. Eng. Proceedings of Spie - the International Society for Optical Engineering, edited by R. H. Bossi and D. M. Pepper (SPIE, San Antonio, TX, USA, 1998), vol. 3399, pp. 97-108.

[5] T. J. Asaki, Fusion Technology 35, 126 (1999).

[6] B. L. Henke, E. M. Gullikson, and J. C. Davis, Atomic Data \& Nuclear Data Tables 54, 181 (1993), as listed at http://www.cxro.lbl.gov/optical_constants/.

[7] D. S. Montgomery, A. Nobile, and P. J. Walsh, Review of Scientific Instruments 75 (2004).

[8] K. A. Nugent, T. E. Gureyev, D. F. Cookson, D. Paganin, and Z. Barnea, Phys. Rev. Lett. 77, 2961 (1996).

[9] P. Cloetens, R. Barrett, J. Baruchel, J.-P. Guigay, and M. Schlenker, J. Phys. D 29, 133 (1996).

[10] B. J. Kozioziemski, J. A. Koch, A. Barty, H. E. Martz, Jr., W.-K. Lee, and K. Fezzaa, Journal of Applied Physics (2005).

[11] S. W. Wilkins, T. E. Gureyev, D. Gao, A. Pogany, and A. W. Stevenson, Nature 384, 335 (1996).

[12] D. Paganin and K. A. Nugent, Phys. Rev. Lett. 80, 2586 (1998).

[13] T. E. Gureyev, C. Raven, A. Snigirev, I. Snigireva, and S. W. Wilkins, J. Phys. D. 32, 563 (1999).

[14] B. E. Allman, P. J. McMahon, J. B. Tiller, K. A. Nugent, D. Paganin, A. Barty, I. McNulty, S. P. Frigo, Y. Wang, and C. C. Retsch, J. Opt. Soc. Am. A 17, 1732 (2000).

[15] Y. Suzuki, N. Yagi, and K. Uesugi, Journal of Synchrotron Radiation 9, 160 (2002).

[16] A. Pogany, D. Gao, and S. W. Wilkins, Review of Scientific Instruments 68, 2774 (1997).

[17] T. E. Gureyev and S. W. Wilkins, J. Opt. Soc. Am. A 15, 579 (1998).

[18] G. Gbur, M. A. Anastasio, Y. Huang, and D. Shi, J. Opt.
Soc. Am. A 22, 230 (2005).

[19] A. J. Martin, R. J. Simms, and R. B. Jacobs, J. Vac. Sci. Technol. A 6, 1885 (1988).

[20] J. K. Hoffer and L. R. Foreman, J. Vac. Sci. Technol. A 7, 1161 (1989).

[21] J. K. Hoffer, L. R. Foreman, J. J. Sanchez, E. R. Mapoles, and J. D. Sheliak, Fusion Tech. 30, 529 (1996).

[22] J. Sater, B. Kozioziemski, G. W. Collins, E. R. Mapoles, J. Pipes, J. Burmann, and T. P. Bernat, Fusion Tech. 35, 229 (1998).

[23] D. N. Bittner, G. W. Collins, E. Monsler, and S. Letts, Fusion Technology 35, 244 (1999).

[24] D. N. Bittner, G. W. Collins, and J. D. Sater, Fusion Science and Technology 44, 749 (2003).

[25] J. A. Koch, T. P. Bernat, G. W. Collins, B. A. Hammel, B. J. Kozioziemski, A. J. MacKinnon, J. D. Sater, D. N. Bittner, and Y. Lee, Fusion Technology 38, 123 (2000).

[26] R. McEachern, C. Alford, R. Cook, D. Makowiecki, and R. Wallace, Fusion Technology 31, 435 (1997).

[27] R. Cook, M. Anthamatten, J. P. Armstrong, S. A. Letts, R. L. McEachern, B. W. McQuilan, and M. Takagi, Proc. of the SPIE 5228, 692 (2003).

[28] P. J. Shull, ed., Nondestructive Evaluation: Theory, Techniques, and Applications (Marcel Dekker, New York, NY, 2002), chap. Radiography, pp. 542-546.

[29] J. M. Cowley, Diffraction Physics (North Holland, Amsterdam, 1981), 2nd ed.

[30] Raytracing was performed using the TracePro ${ }^{\mathrm{TM}}$ commercial optical modeling program. For further information contact Lambda Research Corp., Littleton, MA 01460.

[31] S. C. Mayo, T. J. Davis, T. E. Gureyev, P. R. Miller, D. Paganin, A. Pogany, A. W. Stevenson, and S. W. Wilkins, Optics Ex[ress 11, 2289 (2003).

[32] J. K. Hoffer and L. R. Foreman, Phys. Rev. Lett. 60, 1310 (1988).

[33] J. J. Sanchez and W. H. Giedt, Fusion Science and Technology 45, 253 (2004).

[34] Thermal modeling was performed using the COSMOS commercial finite element method program. For further information contact Structural Research \& Analysis Corp. Los Angeles, CA 90025.

[35] G. E. Childs, L. J. Ericks, and R. L. Powell, Tech. Rep. Monograph No. 131, National Bureau of Standards, Washington, D. C. (1973).

[36] D. E. Perkins, R. W. Ryon, J. J. Haskings, and K. W. Dolan, in 1991 ANST Spring Conference, Nondestructive Characterization for Advanced Technologies (The American Society for Nondestructive Testing, Inc., Oakland, CA, USA, 1991). 